\title{
Journal of Experimental Psychology: Human Perception and Performance
}

Vol. 5, No. 2

MAY 1979

\section{On the Use of a Concurrent Memory Load to Measure Attention and Automaticity}

\author{
Gordon D. Logan \\ Erindale College, University of Toronto \\ Mississauga, Canada
}

\begin{abstract}
The concurrent-memory-load technique identifies attention demands with interactions between reaction-time-task parameters and the size of the load on memory. Three experiments are reported in which a multiple-choice, reaction time task involving two, four, and eight stimulus-response (S-R) alternatives was performed alone and in the retention interval of a short-termmemory task involving ordered recall of eight digits. In Experiment 1, assignment of stimulus letters to response buttons ( $\mathrm{S}-\mathrm{R}$ mapping) was consistent for 6 days but varied on the seventh. Memory load and number of alternatives interacted early in practice, but the interaction diminished over days, and the effects were additive on Day 6 . When the S-R mapping changed on Day 7 , the interaction returned. In Experiment 2, S-R mapping varied daily for 6 days, and the interaction remained stable throughout practice. In Experiment 3, S-R mapping was consistent for 6 days and varied on the seventh, but the memory task was not introduced until Days 6 and 7 . The interaction between memory load and number of alternatives was stronger on Day 7, after the mapping had changed, than it was on Day 6, after practice with consistent mapping. The discussion focuses on the validity of the concurrent-memory-load technique and its relation to another method for measuring attention and automaticity, and on the importance of practice with consistent mapping and practice with dual-task conditions in the development of automaticity.
\end{abstract}

In general terms, attention refers to a central process that coordinates and controls

This research was supported by Grant AO 682 from the National Research Council of Canada. I would like to thank Lee Smith for running the subjects. I am grateful to Ron Fisher, Paul Kolers, Morris Moscovitch, Ben Murdock, Sandor Wiseman, and Jane Zbrodoff for their thoughtful comments and criticism throughout the development of this manuscript, and to Tom Carr, Michael Posner, and Anne Treisman for thorough reviews of an earlier version.

Requests for reprints should be sent to Gordon D. Logan, Department of Psychology, Erindale College, University of Toronto, Mississauga, Ontario, Canada L5L 1 C6. performance in some task environment. Performance is considered automatic to the extent that it is coordinated without attentional control, and the development of automaticity with practice refers to a transfer of control from attention to reliable characteristics of the task environment. The concurrent-memory-load technique has been offered as a method for measuring attention and automaticity, and the experiments reported here were designed to evaluate it.

The technique assumes that the capacity for attentional control is limited, that in principle attentional capacity can be shared by all tasks and task components, and that atten- 
tional capacity is largely responsible for the limitations on short-term-memory performance. It follows that loading memory will reduce the capacity available to a task and interfere with performance to the extent that the task requires attentional capacity. A task of interest is performed both by itself and in the retention interval of a concurrent shortterm-memory task. When reaction time is the major dependent variable, rather general predictions can be made: The attention demands of components of the reaction time task will be related to the magnitude of interactions between parameters representing those components and the size of the load on memory; the larger the interaction, the greater the attention demand. Automatic components are assumed to demand no attention and so will be indicated by the absence of interactions with memory load. The development of automaticity with practice will appear as a transition from interaction to additivity (Egeth, 1977; Logan, 1978; also see Baddeley \& Hitch, 1974). The plan of this article is to elaborate the assumptions so that the predictions can be articulated in terms of current theories of attention and to determine whether the predictions (interaction, additivity, and a transition from interaction to additivity) can be confirmed experimentally.

The assumptions that attentional capacity is limited and can be shared by all tasks can be interpreted in three ways: First, attentional capacity may be the only limitation on performance so that all capacity-limited tasks share the same capacity (e.g., Broadbent, 1958; Moray, 1967). Second, attentional capacity may be one of many capacities limiting performance, distinguished by its function as an executive controller. Attentional capacity is shared by all tasks in the sense that all tasks require some degree of attentional control (e.g., Kahneman, 1973; McLeod, 1977 ; Posner \& Snyder, 1975). Third, there may be many capacities limiting performance, none of which is identified uniquely with attention. A single attentional capacity is not shared by all tasks. Instead, control is heterarchic; different capacities assume executive control in different tasks (Allport, Antonis, \& Reynolds, 1972; Treis- man, 1969; Turvey, 1977). The first view can be ruled out on the basis of existing data: There appear to be many independent influences on performance, and each may be viewed as a capacity limitation (e.g., the processing stages described by Sternberg, 1969; also see Allport, 1971; Logan, 1976; Shwartz, 1976; Treisman \& Davies, 1973). The choice between the second and third views (i.e., the choice between a single executive and heterarchic control) is important in interpreting data obtained with the concurrent-memory-load technique since heterarchic control violates the assumption that all tasks share one capacity. The issue may be hard to settle empirically, and an attempt to do so is beyond the scope of this article. But since short-term memory seems important in a wide variety of tasks (e.g., Baddeley \& Hitch, 1974; Chase \& Simon, 1973; Graesser \& Mandler, 1978; Hitch, 1978; Wanner \& Shiner, 1976), the distinction between a single executive and heterarchic control may be more apparent than real; at worst, the technique may assess one of the more commonly used capacities for control.

A more immediate concern is the implication of both views that more than one capacity may contribute to the effect of a single manipulation of load. If the dependent variable is reaction time, the capacities involved may be revealed by analyzing interactions between effects: Variables that reflect a common capacity will interact, whereas variables that reflect separate capacities will have additive effects. The capacities contributing to an effect can be identified by determining which variables the effect interacts with (Sternberg, 1969). For this reason, interactions with memory load are used to identify variables that reflect the attention demands of a task.

The use of a concurrent short-term-memory task to vary the load on capacity rests on the assumption that short-term retention is limited by attentional capacity and on some empirical considerations. The assumption derives from a historical association between attention and short-term retention (Daniels, 1895 ; James, 1890), which endures in modern theory (Atkinson \& Shiffrin, 1968; 
Broadbent, 1958; Kahneman, 1973; Waugh \& Norman, 1965). A limited capacity for activation is a performance assumption frequently shared by theories of memory and theories of attention; theories that identify short-term memory with the activation of permanent memory (J. R. Anderson, 1976; Baddeley \& Hitch, 1974; Craik \& Lockhart, 1972) go hand in hand with theories that identify attentional control with the selective activation of key processing structures (Kahneman, 1973; Norman, 1968; Posner \& Snyder, 1975; Shallice, 1972). The concurrent-memory-load technique makes explicit the assumption that the capacities are one and the same.

Four empirical considerations support the use of a concurrent short-term-memory task to load attention. First, the dual-task design allows the amount of attention available to be varied (i.e., by varying the demands of the concurrent task) without changing conditions of the task in question so that the possibility that loading has created a new task is reduced. Second, retention requires no overt perception or response so that interpretations based on overloading nonattentional peripheral capacities can be ruled out a priori (e.g., Vroon, 1973). However, it must still be assumed that the tasks share no central capacity other than attention. Third, typical retention intervals are substantially longer than typical reaction times, so the technique can be used to test a wide variety of tasks with only minor changes in procedure. Fourth, as mentioned earlier, short-term retention has been shown to interfere with a wide variety of tasks and thus lends credibility to the assumption that it is involved in all tasks.

It follows from these assumptions that attention demands will be related to the amount by which loading memory increases reaction time (i.e., the difference between dual-task and single-task reaction times). For a given memory load, the effect will be larger in conditions that demand more attention and smaller in conditions that demand less. Thus, the relation between attention demands and task conditions will be revealed as an interaction between memory load and some parameter representing a dimension along which conditions differ; a null interaction will indicate equal attention demands. When variation in conditions reflects the load on some specific task component, a null interaction means that the component functions automatically.

In summary, the concurrent-memory-load technique rests on theory that predicts the existence of particular patterns of data (interaction and additivity) appearing in a particular order as a function of practice (interaction, then additivity). The validity of the technique depends, in part, on whether the predicted patterns appear in real data in the predicted order.

Most studies that have used the technique have found additivity, even at the beginning of practice. Table 1 lists nine parameters whose effects on reaction time have been shown to be additive with respect to memory load (Egeth, 1977 ; Logan, 1976, 1978, Note 1). By contrast, only three parameters have been shown to interact with memory load: First, Keele and Boies (1973) found an interaction with stimulus predictability such that more predictable stimuli suffered less from loading than did less predictable stimuli. Second, Crowder (1967) found an interaction with spatial S-R compatibility in a 10-choice task such that more compatible S-R mappings suffered less from loading than did less compatible mappings. However, Egeth (1977) could not replicate the interaction in a two-choice task. Third, Sternberg (1969, Experiment 5) and Logan (1978, Experiments 1 and 2) found interactions with target-set size in a memory-search task such that smaller target sets (i.e., those containing fewer items) suffered less from loading than did larger ones. The interactions in memory search, however, have not replicated well with concurrent activities other than short-term retention; some experimenters found interactions (Howard, 1975) and others did not (Briggs, Peters, \& Fisher, 1972; Griffith \& Johnston, 1977). Thus, it seems that the evidence for additivity is more solid than the evidence for interaction, and this is a problem.

Egeth (1977), having found nothing but 
Table 1

Parameters of Reaction Time Tasks Whose Effects Have Been Shown To Be Additive With Respect to Memory Load, Organized According to Their Influence on Hypothesized Stages of Processing

\begin{tabular}{llll}
\hline \multicolumn{1}{c}{ Encoding } & Comparison & $\begin{array}{c}\text { Decision } \\
\text { type }\end{array}$ & Response selection \\
\hline $\begin{array}{l}\text { Contrast } \\
\text { Brightness }_{\text {Masking condition }}\end{array}$ & $\begin{array}{l}\text { discriminability } \\
\text { array size } \\
\text { bar-marker-cue } \\
\text { condition }\end{array}$ & yes-no & $\begin{array}{l}\text { verbal S-R compatibility } \\
\text { response type (vocal vs. } \\
\text { manual) }\end{array}$ \\
\hline
\end{tabular}

Note. $\mathrm{S}-\mathrm{R}=$ stimulus-response.

a Logan, Note 1.

b Egeth, 1977.

additive effects in three stages of the same task, suggested that interactions might never occur. The memory-load effect, he argued, might simply reflect the time required to switch attention from the memory task to the reaction time task, and this time might be constant for all tasks. However, switching time may not be constant. Switching attention may itself require capacity so that switching time would increase with the demands of both tasks (i.e., since less capacity would be available to speed switching; see Laabs \& Stager, 1976 ; LaBerge, 1973 ; Proctor \& Fisicaro, 1977). If it were so, memory load would interact with parameters that represent variation in attention demand and would have additive effects with parameters that do not (i.e., parameters that reflect automatic components; also see Logan, 1978). Regardless, the problem posed by Egeth's suggestion would be resolved most satisfactorily by convincing evidence of interaction.

Perhaps the most important prediction derived from the assumptions underlying the concurrent-memory-load technique is the transition from interaction to additivity. It identifies interaction and additivity as different points on one dimension representing the development of automaticity, and suggests that the dimension itself might be a more revealing object of study than any of the points along it. In particular, to demonstrate that a transition from interaction to additivity occurs under conditions that are believed to be necessary and sufficient for the development of automaticity would be an important step toward the validation of the technique.
In other contexts, it has been argued that extended practice on the same task is necessary to produce automaticity (Bryan \& Harter, 1899; LaBerge \& Samuels, 1974; Solomons, 1899). Recently, Shiffrin and Schneider (1977) suggested that the mapping or assignment of stimuli onto responses must be consistent throughout practice if automaticity is to develop, and they provided impressive evidence in support of their position, using a technique different from the concurrent-memory-load procedure to access automaticity. Alternatively, Neisser (1976) and his colleagues (Spelke, Hirst, \& Neisser, 1976) argued that in divided attention situations like the concurrent-memory-load procedure, practice with dual-task conditions is necessary to produce automaticity, and they showed that under some conditions it is at least sufficient (but see Allport et al., 1972; Bahrick, Noble, \& Fitts, 1954).

To test these propositions and to establish the existence of interactions convincingly, I conducted three experiments to examine the importance of practice with consistent mapping and practice with dual-task conditions as factors affecting the development of automaticity in a multiple-choice, reaction time task. The multiple-choice task was employed to broaden the range of tasks to which the concurrent-memory-load technique had been applied and to test a hypothesis derived in earlier investigations (Logan, 1978) that memory load interacts with parameters affecting the amount of preparation required for a task. In the context, preparation refers to the recruitment and adjustment of exist- 
ing processing resources so that their combined activity satisfies the demands of the task (i.e., what must be kept in mind to perform correctly; see Doll, 1969; Klapp, 1976). Indeed, the parameters that interact with memory load (stimulus predictability, spatial S-R compatibility, and target-set size) seem to affect the amount of preparation required. In the present experiments, choice conditions involving more alternatives were expected to require more preparation and thus to produce larger memory-load effects.

In each experiment, subjects performed a multiple-choice task with two, four, and eight S-R alternatives (letters mapped onto buttons) both by itself as a single task and in the retention interval of a short-term-memory task that required ordered recall of eight digits. Attention demands were expected to be revealed as interactions between memory load and number of alternatives; automaticity was expected to be revealed by additive effects; and the development of automaticity, by a reduction in the magnitude of the interaction with practice.

The first experiment was designed to demonstrate that practice with consistent mapping and practice with dual-task conditions together are sufficient conditions for automaticity to develop. Subjects used the same mapping of stimulus letters onto response buttons for 6 days of practice, then switched to a new mapping on the seventh day. Memory load and number of alternatives were expected to interact in the initial sessions, and the interaction was expected to diminish with practice until at some point the effects would be additive. The change in mapping on the seventh day was intended as a test of the importance of practice with consistent mapping. If such practice is a necessary condition for the development of automaticity, performance with the new mapping should not be automatic despite the practice with dual-task conditions. Thus, the interaction between memory load and number of alternatives should be greater on Day 7 with the new mapping than it was on Day 6 with the old mapping. On the other hand, if practice with consistent mapping is not a necessary condi- tion for the development of automaticity, performance with the new mapping should be just as automatic as performance with the old; the interaction on Day 7 should be no larger than the one on Day 6 .

Practice with consistent mapping and practice with dual-task conditions were correlated in the procedure of Experiment 1. Experiments 2 and 3 were designed to remove the correlation so that the separate effects of the different conditions of practice could be evaluated.

The second experiment pitted practice with dual-task conditions against practice with varied mapping. Subjects practiced the choice task for 6 days under single- and dualtask conditions (i.e., no memory task vs. concurrent memory task), and the mapping of stimulus letters onto response buttons changed daily. If practice with consistent mapping is necessary for automaticity to develop, none should develop here; the interaction between memory load and number of alternatives should remain stable throughout practice. If, on the other hand, practice with dual-task conditions is sufficient to produce automaticity, performance should become automatic; the initial interaction should diminish over practice until additivity is attained.

The third experiment pitted practice with consistent mapping against practice in singletask conditions. As in Experiment 1, subjects practiced one S--R mapping for 6 days, then switched to a new mapping on the seventh. Unlike Experiment 1, the concurrent memory task was not introduced until Day 6; dual-task data were obtained only on Days 6 and 7 . If practice with consistent mapping is sufficient to produce automaticity, performance on Day 6 should be just as automatic as it was after the same amount of practice with consistent mapping in Experiment 1; the effects should be additive. Further, if such practice is necessary for automaticity to develop, performance with the new mapping on Day 7 should not be automatic; the interaction on Day 7 should be greater than the one on Day 6. On the other hand, if practice with dual-task conditions is a necessary condition for automaticity to develop, perform- 
Table 2

Letters, Mappings, and Sets of Mappings Used in Choice Tasks

\begin{tabular}{cccc}
\hline & \multicolumn{3}{c}{$\begin{array}{c}\text { No. of stimulus- } \\
\text { response alternatives }\end{array}$} \\
\cline { 2 - 4 } Set & 2 & 4 & 8 \\
\hline 1 & DT & PSCL & BFKHMRVX \\
2 & TD & SPLC & FHBRKXMV \\
3 & DN & CLPS & HRFXBVKM \\
4 & ND & LCSP & KBMFVHXR \\
5 & NT & PCLS & XVRMHKFB \\
6 & TN & LSPC & VMXKRBHF \\
\hline
\end{tabular}

ance should not be automatic the first time the memory task is introduced; the interaction on Day 6 should be as strong as the interaction on Day 1 of Experiment 1 when the memory task was also introduced for the first time. Moreover, performance with the new mapping on Day 7 should be no less automatic than performance with the old one on Day 6; the interaction on Day 7 should be no larger than the one on Day 6 .

Since the three experiments were variations of the same procedure, they are described in a single Method section. Departures from the general method are noted where appropriate.

\section{Method}

\section{Subjects}

Each experiment used a different group of six undergraduate students and laboratory staff from Erindale College. In each experiment, three were male and three were female. Subjects in Experiments 1 and 3 served for seven 1-hour sessions, and subjects in Experiment 2 served for six 1-hour sessions. All subjects were paid for their participation and were tested for each session within 1 hour of the same time of day.

\section{Apparatus and Stimuli}

The choice task. The stimuli for the choice task were black letters on a white field, rear-projected onto a semiopaque screen by a carousel slide projector (Kodak Model $650 \mathrm{H}$ ) equipped with a tachistoscopic shutter (Uniblitz Model 26), under the control of Grason-Stadler logic and timing devices. A second projector, equipped with a tachistoscopic shutter from the same manufacturer, exposed a black fixation point in the center of a white field whenever the stimulus field was not exposed.
The letters were made from black uppercase Letraset (No. 1570) mounted in the center of 35$\mathrm{mm}$ glass slides. When projected on the screen and viewed from a distance of $75 \mathrm{~cm}$ (a headrest was used to maintain a constant viewing distance), each letter subtended about $.45^{\circ} \times .53^{\circ}$ of visual angle. From the subject's viewpoint, the letters appeared in the center of a white rectangular field which subtended about $9.93^{\circ}$ horizontally and $6.49^{\circ}$ vertically. The field was constructed by arranging opaque masks on the back of the screen. The luminance of the fixation and stimulus fields was about $14 \mathrm{ftL}$. $\left(48 \mathrm{~cd} / \mathrm{m}^{2}\right)$.

The letters were exposed for $500 \mathrm{msec}$ unless the subject responded sooner. The apparatus was programmed such that a button-press response (required for the choice task) would remove the current slide from the projector, advance the slide tray, and insert the slide for the next trial. Thus, a button-press response with a latency less than $500 \mathrm{msec}$ would terminate the exposure of the current slide. Since removing the current slide and inserting the next one took about $1 \mathrm{sec}$, fast responses did not allow a "preview" of the next slide.

The major variables in the choice task were the number of $S-R$ alternatives (two, four, or ejght) and the (six) different mappings of stimuli onto responses. The stimuli were chosen from a set of 15 consonants; the responses were chosen from a set of eight buttons. Eight consonants were assigned to the eight-choice condition. Six different mappings were constructed by selecting six permutations of the eight consonants and assigning them to the eight response buttons (i.e., the first consonant of each permutation to the leftmost button, the second to the next to leftmost, etc.; see Table 2). Similarly, four of the remaining consonants were assigned to the four-choice condition, and six fourchoice mappings were constructed by selecting six permutations of the four consonants and assigning them to the response buttons. The three remaining consonants were used in the two-choice condition. Six mappings of two stimuli onto two responses were constructed by permuting the three possible combinations of two consonants from the set of three and assigning each permutation and combination to the response buttons. Six sets of mappings were constructed by combining one mapping from each choice condition (two, four, and eight). The letters and mappings used in each choice condition appear in Table 2. The columns represent choice conditions, and the rows represent the six sets of mappings.

The response buttons were eight standard telegraph keys arranged in an arc, with the centers of adjacent buttons separated by $4 \mathrm{~cm}$. The buttons were assigned compatibly to the four fingers of each hand, and subjects rested their fingers on the buttons before stimulus presentation. The eightchoice condition used all eight buttons, the fourchoice condition used the middle four buttons (which were assigned to the index and middle fingers of each hand), and the two-choice condition 
used the middle two buttons (which were assigned to the index fingers).

The memory task. The stimuli for the memory task were lists of eight different digits. A different list was prepared for each trial in each session. The lists were tape recorded at a rate of $.75 \mathrm{sec}$ per digit and were played back through a speaker in front of the subject at a comfortable listening level. A warning signal ("ready?") preceded the first digit in each list by $1.5 \mathrm{sec}$, and recall was signaled by a $500-\mathrm{msec}, 1000-\mathrm{Hz}$ sine tone presented through an adjacent speaker about $6 \mathrm{sec}$ after the last digit in each list.

\section{Procedure}

There were three types of trials: single-task choice, single-task memory, and dual task. A dualtask trial consisted of the following sequence of events: (a) the presentation of a memory list, (b) the exposure of a letter, (c) the subject's response to the letter, (d) the presentation of the tone to signal recall, and (e) the subject's recall of the memory list. Single-task choice trials omitted Events a, d, and e; single-task memory trials omitted Events b and c but kept the retention interval the same as in dual-task trials.

Initially, and whenever it changed, subjects were told the $\mathrm{S}-\mathrm{R}$ mapping that was relevant to each block of trials. When a new mapping was introduced, subjects learned it to a criterion of three consecutive correct repetitions and then performed 16 practice trials on the reaction time apparatus before choice-task data were collected. Whenever they were uncertain of the current mapping, subjects were allowed to ask what it was. They were instructed to respond to the choice task as quickly and as accurately as possible.

Subjects were told to recall the eight digits in the order in which they were presented. They were told that the memory task was more important than the choice task and that they should optimize performance on the memory task in all conditions. Moreover, they were told the number of digits they recalled correctly and the nature of their errors immediately after each trial, but they were given no feedback about speed or accuracy in the choice task. These instructions and feedback conditions defined the memory task as the primary task and the choice task as the secondary task so that the bulk of the dual-task interference would appear in the secondary, choice-task data (Posner \& Boies, 1971; Shulman \& Fisher, 1972).

The three experiments were procedurally identical except for the differences described below:

Experiment 1. Each subject in Experiment 1 received one set of mappings (i.e., one row of Table 2) for six consecutive sessions. Each of the six sets of mappings was assigned to a different subject. Every subject returned for a seventh session to receive a new set of mappings selected from the rows of Table 2.

Memory-load conditions were nested within choice conditions and were balanced for order separately (see below). The order of the three choice conditions (two, four, and eight alternatives) varied across subjects each day (each of the six possible orders was assigned to one subject) and within subjects across days (each subject received the six possible orders in a different sequence, determined by the rows of a balanced $6 \times 6$ Latin square). The order of choice conditions on the seventh day was the same as on the first.

Each session began with appropriate instructions, followed by 12 single-task memory trials, 144 singleand dual-task choice trials (24 trials in each combination of choice and single-dual task conditions), and ended with 12 single-task memory trials. Subjects completed one single-task and one dual-task block of 24 trials in each choice condition before moving on to the next. Each day, half of the subjects had single-task blocks before dual-task blocks (within each choice condition), and half had the opposite. The order of single-task and dual-task choice blocks alternated within subjects over days.

Experiment 2. Each subject in Experiment 2 received a different set of S-R mappings (one row of Table 1) each session for 6 days in an order determined by the rows of a balanced $6 \times 6$ Latin square. The order of choice conditions and single-task and dual-task blocks within choice conditions was balanced within and between subjects as in Experiment 1. Note that the sets of S-R mappings and orders of choice conditions were necessarily confounded because of the small number of subjects (six). As in Experiment 1, each session began with appropriate instructions and 12 single-task memory trials, followed by 144 single- and dual-task choice trials, and ended with 12 single-task memory trials.

Experiment 3. This experiment was an exact replication of Experiment 1 except that the memory task was not introduced until the sixth session. Until then, each subject completed 144 single-task choice trials each day. The 144 trials were divided into blocks of 24 , and each subject completed two blocks of 24 trials in each choice condition before going on to the next, mimicking the single- and dual-task procedure in Experiment 1. The sixth and seventh sessions began with appropriate instructions, followed by 12 single-task memory trials, followed by 144 single- and dual-task choice trials, and ended with 12 single-task memory trials. In Session 6, subjects received the same mappings they had received for the first five sessions; in Session 7, the sets of mappings changed according to the procedure of Experiment 1. The ordering of choice conditions between and within subjects and sessions was accomplished as in Experiment 1.

\section{Data. Analysis}

Choice task. In all three experiments, each subject completed 24 trials in each combination of choice-task and memory-load conditions each session. The mean reaction time for correct responses in each of these combinations was computed for each subject. The scores were submitted to various 
three-way within-subjects analyses of variance, with number of alternatives (two, four, or eight), memory load (zero or eight), and days as factors.

Three analyses were performed on the reaction times from Experiment 1. The first included data from all seven sessions; the second and third included subsets of these data to provide comparisons equivalent in power to comparisons made in Experiments 2 and 3 , respectively. The second included data from Days $1-6$ to assess the effects of practice with memory load and consistent mapping. By excluding data from Day 7 , these effects could be seen directly in the interaction terms without further computation. The third included data from Days 6 and 7 to assess the effects of changing S-R mapping after practice with memory load and consistent mapping.

One analysis was performed in Experiment 2, including data from all six sessions. Experiment 3 involved two analyses. One included data from Days 1-5 to assess the effects of practice with consistent mapping. The other included data from Days 6 and 7 to assess (a) the extent to which automaticity had developed on Day 6 after practice with consistent mapping but not memory load and (b) the effects of changing S-R mapping after such practice.

The error data were collapsed in the same manner as the reaction times. The proportion of errors in each combination of choice-task and memory-load conditions was computed for each subject for each session. In many conditions the error rates were too low for statistical analysis (i.e., there were several scores of zero, particularly in single-task conditions), so none were attempted.

Memory task. In all three experiments, in those sessions that involved the memory task, each subject recalled 24 strings of eight digits in each choice-task condition and 24 strings in two blocks of 12 trials in the single-task condition. The single-task data were collapsed across blocks, and the mean number of digits recalled in correct order was computed for each subject in each condition each day. These scores were submitted to two-way within-subjects analyses of variance, with conditions $(0,2,4$, or 8 concurrent S-R alternatives) and days as factors.

Three analyses were performed on the data from Experiment 1, one including all the data, one including data from Days 1-6, and one including data from Days 6 and 7, complementing the three analyses of the reaction time data. Experiment 2 involved one analysis which included data from all six sessions, and Experiment 3 involved one analysis which included data from Days 6 and 7 (i.e., the only days on which the memory task was performed).

\section{Experiment 1}

Results

Choice task. The mean reaction times in each combination of choice and memory-load conditions are plotted $^{1}$ in Figure 1. Two aspects of the data are relevant: (a) the possibility of a transition from interaction to additivity, which would reflect the development of automaticity, and (b) the possibility of an increased interaction on Day 7 when the mapping changed, which would reflect a recovery of interference. Both effects are apparent in the figure. First, the effects of memory load were greater the larger the number of alternatives (i.e., interacted) early in practice, but this proportionality diminished over days. By Days 5 and 6, memory load had the same effect for all numbers of alternatives (i.e., the effects were additive). Second, when the mapping changed on Day 7 , the proportionality of effects returned; memory load interfered more with the choice task the larger the number of alternatives.

These effects were also apparent in the statistical analyses. First, reaction time increased with memory load, $F(1,5)=43.11$, $p<.01$, and with number of alternatives, $F(2,10)=47.65, p<.01$. The effects were proportional early in practice, as reflected by the two-way interaction between memory load and number of alternatives, $F(2,10)=$ $11.02, p<.01$, but the proportionality diminished over days, as reflected by the threeway interaction between memory load, number of alternatives, and days, $F(10,50)=$ $2.98, p<.01$. It was clear that the effects were additive on Day 6. A contrast comparing the memory-load effect in the eight-alternative condition with the effect in the twoalternative condition on Day 6 produced an $F$ less than one whether the error term (derived from the interaction between subjects, memory load, number of alternatives, and

1 In all three experiments, reacrion times are plotted as a function of the absolute number of alternatives instead of the usual $\log _{2}$ number of alternatives (Hick, 1952; Hyman, 1953) because the linear fit to the former was better than to the latter. In Experiments 1, 2, and 3, respectively, the linear fit accounted for $88 \%, 96 \%$, and $86 \%$ of the variance component associated with number of alternatives, whereas the $\log _{\alpha}$-linear fit accounted for $85 \%, 94 \%$, and $83 \%$. Although the data deviate from the Hick-Hyman law in each experiment, the discrepancy is not large. 
days) came from the analysis of the data from Days 6 and 7 or from the analysis of all the data.

Second, there was evidence of a recovery of interference on Day 7 when the mapping changed. Interference on Days 6 and 7 can be compared in the simple interaction between memory load, number of alternatives, and days (Days 6 and 7), which was significant in the analysis of data from all seven sessions, $F(2,60)=4.77, p<.05$, but not in the analysis of data only from Days 6 and $7, F(2,10)=1.84, p>.05$. However, contrasts computed from the latter analysis showed that the memory-load effect with eight alternatives increased from Day 6 to Day $7, F(1,10)=7.34, p<.05$, but the effect with two alternatives did not change over days, $F(1,10)<1$.

A final point of interest is that the proportionality of effects was about as strong on Day 7 at it was on Day 1. Memory load increased the slope of the best fitting linear function relating reaction time to number of alternatives by about $46 \mathrm{msec} / \mathrm{alternative} \mathrm{on}$ Day 1 and about $47 \mathrm{msec} /$ alternative on Day 7. A simple interaction between memory

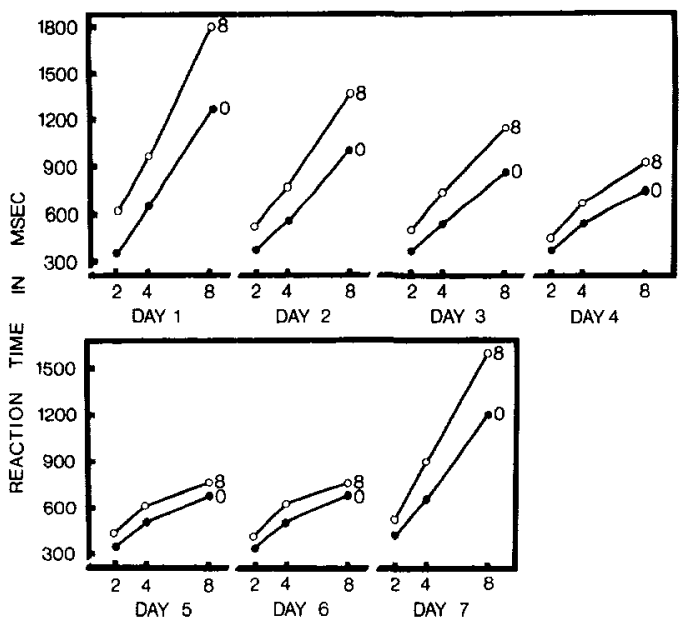

Figure 1. Mean reaction times in the choice task of Experiment 1 each day as a function of number of stimulus-response alternatives. (Memory-load conditions constitute the parameter: $0=$ no digits in memory ; $8=$ eight digits in memory.)

load, number of alternatives, and days (Days 1 and 7 ) was not significant, $F(2,60)<1$. The error data, presented in Table 3 , show similar trends.

Memory task. The mean number of digits recalled in correct order in each condition

Table 3

Proportion of Errors in Choice Task Each Day as a Function of Number of $S-R$ Alternatives (Experiment 1)

\begin{tabular}{|c|c|c|c|c|c|}
\hline \multirow[b]{2}{*}{ Day } & \multirow{2}{*}{$\begin{array}{l}\text { Memory load } \\
\text { (no. of digits) }\end{array}$} & \multicolumn{4}{|c|}{ No. of $\mathrm{S}-\mathrm{R}$ alternatives } \\
\hline & & 0 & 2 & 4 & 8 \\
\hline 1 & $\begin{array}{l}0 \\
8\end{array}$ & $-(7.04)$ & $\begin{array}{l}.05 \\
.04(6.89)\end{array}$ & 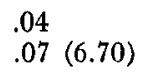 & $\begin{array}{l}.02 \\
.11(6.10)\end{array}$ \\
\hline 2 & $\begin{array}{l}0 \\
8\end{array}$ & $-(7.20)$ & $\begin{array}{l}.05 \\
.04(6.75)\end{array}$ & .03 & $\begin{array}{l}.03 \\
.09(6.43)\end{array}$ \\
\hline 3 & $\begin{array}{l}0 \\
8\end{array}$ & $-(7.22)$ & $\begin{array}{l}.03 \\
.03(7.00)\end{array}$ & .03 & $\begin{array}{l}.06 \\
.08(6.68)\end{array}$ \\
\hline 4 & $\begin{array}{l}0 \\
8\end{array}$ & $-(7.47)$ & $\begin{array}{l}.06 \\
.04(7.28)\end{array}$ & $\begin{array}{l}.08 \\
.03(7.11)\end{array}$ & $\begin{array}{l}.04 \\
.08(6.97)\end{array}$ \\
\hline 5 & $\begin{array}{l}0 \\
8\end{array}$ & $-(7.58)$ & $\begin{array}{l}.08 \\
.08(7.03)\end{array}$ & $\begin{array}{l}.10 \\
.03(7.28)\end{array}$ & $\begin{array}{l}.04 \\
.06(7.40)\end{array}$ \\
\hline 6 & $\begin{array}{l}0 \\
8\end{array}$ & $-(7.61)$ & $\begin{array}{l}.04 \\
.06(7.52)\end{array}$ & $\begin{array}{l}.05 \\
.06(7.12)\end{array}$ & $\begin{array}{l}.04 \\
.08(7.15)\end{array}$ \\
\hline 7 & $\begin{array}{l}0 \\
8\end{array}$ & $-(7.84)$ & .07 & $\begin{array}{l}.05 \\
.11(7.30)\end{array}$ & $\begin{array}{l}.06 \\
.17(6.13)\end{array}$ \\
\hline
\end{tabular}

Note. $\mathrm{S}-\mathrm{R}=$ stimulus-response. Zero S-R alternatives represent single-task memory trials. Numbers in parentheses are mean numbers of digits recalled in correct order. 
each day appears in Table 3. Early in practice (Days 1-3), memory performance was affected by choice task conditions, being worse the larger the number of alternatives, complementing the interaction between memory load and number of alternatives at the same stage of practice. Later (Days 5 and 6 ), choice conditions had a negligible effect on memory performance, complementing the additivity of memory-load and number-ofalternatives effects found in the corresponding reaction time data. Finally, when the mapping changed on Day 7 , recall performance dropped dramatically in the eight-choice condition, complementing the return of the interaction in the reaction time data.

These effects were apparent in the statistical analyses. First, the main effect of conditions was significant, $F(3,15)=10.96$, $p<.01$, as was the interaction between conditions and days, $F(15,75)=1.85, p<.05$, which reflects a transition analogous to the transition from interaction to additivity in the reaction time data. Second, Fisher's least significant difference (LSD) test (Kirk, 1968), using the interaction between subjects, conditions, and days from the analysis of Days 6 and 7 to compute an error term, found no significant difference between any of the conditions on Day 6, which reflects the additivity observed in the corresponding reaction time data. However, when the LSD test was repeated, using an error term based on data from all seven sessions, recall in four- and eight-choice conditions was found to be significantly worse than recall in twochoice and single-task conditions $(p<.05)$.

Third, the simple interaction between conditions and days (Days 6 and 7) was marginally significant in the analysis of Days 6 and $7, F(3,15)=2.87, p<.08$, but was highly significant in the analysis of all seven sessions, $F(3,90)=6.49, p<.01$, which reflects a recovery of interference on Day 7 . Fisher's LSD test was applied to the data of Day 7, and the eight-choice condition was found to produce significantly poorer recall than did any other condition $(p<.05)$ when the error term was computed from the analysis of Days 6 and 7. When the error term was computed from the analysis of all the data, eight-choice recall was worse than all others, and four-choice recall was worse than single-task recall $(p<.05)$.

\section{Discussion}

This experiment was designed to determine whether practice with consistent mapping and practice with dual-task conditions together were stufficient to produce automaticity and to test the necessity of practice with consistent mapping by varying the mapping on Day 7. The data suggest that the two kinds of practice together are sufficient to produce automaticity in that the appropriate interaction appeared early and climinished throughout practice, until finally, additive effects were observed. The findings also implicate practice with consistent mapping as a necessary condition for the development of automaticity because performance with the new mapping on Day 7 was less automatic than performance with the old mapping on Day 6.

\section{Experiment 2}

\section{Results}

Choice task. Mean reaction times in each combination of choice and memory-load conditions each day are plotted in Figure 2. The relevant aspect of these data is the possibility of a transition from interaction to additivity, which would reflect the development of automaticity with practice in dual-task conditions while the mapping varied from day to day. The figure shows no evidence of such a transition: The effects of memory load and number of alternatives were proportional early in practice and remained so throughout the experiment.

This effect was apparent in the statistical analysis. Reaction time increased with number of alternatives, $F(2,10)=132.47, p<$ .01 , and with memory load, $F(1,5)=37.58$, $p<.01$, and the interaction between them was highly significant, $F(2,10)=12.95$, $p<.01$. Neither the interaction between memory load and days, $F(5,25)<1$, nor the interaction between memory load, num- 
ber of alternatives, and days, $F(10,50)=$ $1.10, p>.05$, was significant; the interaction between memory load and number of alternatives remained stable over 6 days of practice.

Again, the error data corroborated the findings with reaction time. Mean error rates in each condition each day appear in Table 4.

Memory task. The mean number of digits recalled in correct order in each condition each day appears in Table 4. Complementing the reaction time data, recall performance was affected by choice task conditions such that dual-task recall was poorer than singletask recall, and in the dual-task conditions, recall was poorer the larger the number of alternatives. These effects remained stable throughout practice.

Statistical analysis supported these observations: The main effects of conditions, $F(3,15)=44.61, p<.01$, and days, $F(5$, $25)=9.06, p<.01$, were significant, but the interaction between them was not, $F(15$, 75) $<1$

\section{Discussion}

This experiment pitted practice with dualtask conditions against practice with varied
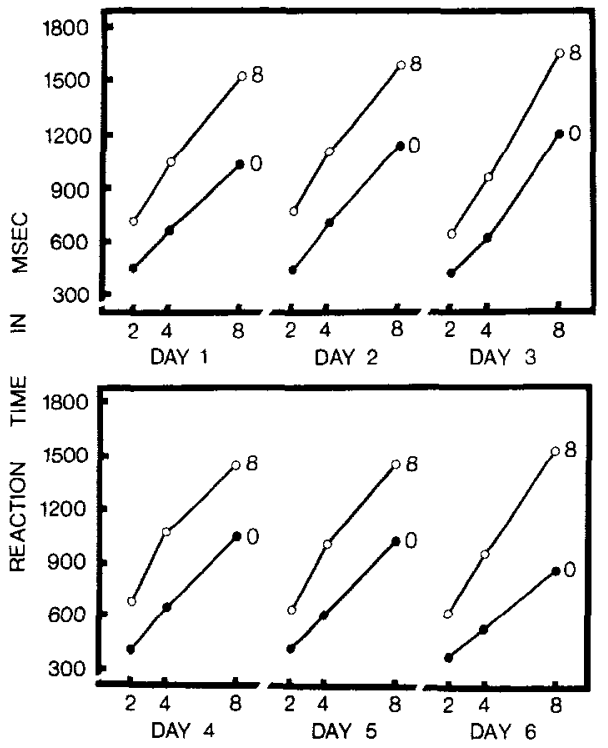

Figure 2. Mean reaction times in the choice task of Experiment 2 each day as a function of number of stimulus-response alternatives. (Memory-load conditions constitute the parameter: $0=$ no digits in memory ; $8=$ eight digits in memory.)

mapping and found that automaticity did not develop. In both the reaction time data and the recall data, dual-task interference was greater the larger the number of alternatives

Table 4

Proportion of Errors in Choice Task Each Day as a Function of Number of $S-R$ Alternatives (Experiment 2)

\begin{tabular}{|c|c|c|c|c|c|}
\hline \multirow[b]{2}{*}{ Day } & \multirow{2}{*}{$\begin{array}{l}\text { Memory load } \\
\text { (no. of digits) }\end{array}$} & \multicolumn{4}{|c|}{ No. of S-R alternatives } \\
\hline & & 0 & 2 & 4 & 8 \\
\hline 1 & $\begin{array}{l}0 \\
8\end{array}$ & $-(6.18)$ & .03 & .07 & $\begin{array}{l}.08 \\
.22(5.21)\end{array}$ \\
\hline 2 & $\begin{array}{l}0 \\
8\end{array}$ & $-(6.86)$ & .04 & .06 & .11 \\
\hline 3 & $\begin{array}{l}0 \\
8\end{array}$ & $-(6.97)$ & .03 & $\begin{array}{l}.06 \\
.11(6.14)\end{array}$ & $\begin{array}{l}.08 \\
.23(5.54)\end{array}$ \\
\hline 4 & $\begin{array}{l}0 \\
8\end{array}$ & $-(6.97)$ & $.06 \quad .02(6.48)$ & $\begin{array}{l}.08 \\
.08(6.29)\end{array}$ & $\begin{array}{l}.09 \\
.22(5.92)\end{array}$ \\
\hline 5 & $\begin{array}{l}0 \\
8\end{array}$ & $-(7.30)$ & .08 & $\begin{array}{l}.08 \\
.08(6.54)\end{array}$ & $\begin{array}{l}.10 \\
.20(6.15)\end{array}$ \\
\hline 6 & $\begin{array}{l}0 \\
8\end{array}$ & $-(7.12)$ & $\begin{array}{l}.06 \\
.07(6.63)\end{array}$ & $\begin{array}{l}.08 \\
.10(6.44)\end{array}$ & $\begin{array}{l}.12 \\
.17(6.12)\end{array}$ \\
\hline
\end{tabular}

Note. $\mathrm{S}-\mathrm{R}=$ stimulus-response. Zero $\mathrm{S}-\mathrm{R}$ alternatives represent single-task memory trials. Numbers in parentheses are mean numbers of digits recalled in correct order. 


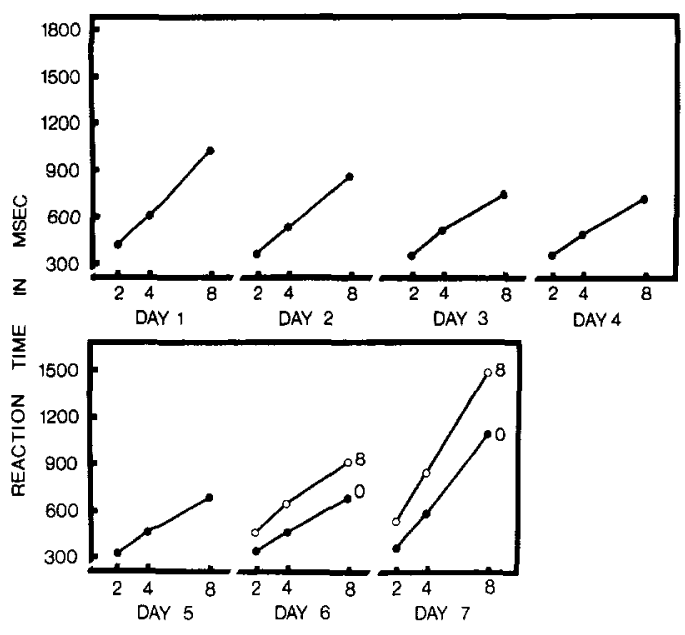

Figure 3. Mean reaction times in the choice task of Experiment 3 each day as a function of number of stimulus-response alternatives. (Only single-task trials were run on Days 1-5; on Days 6 and 7, $0=$ no digits in memory, and $8=$ eight digits in memory.)

and remained so throughout practice. This pattern of results contrasts sharply with the development of automaticity observed in Experiment 1, and together they suggest two conclusions. First, practice with consistent mapping seems to be a necessary condition for the development of automaticity since automaticity developed with consistent mapping but not with varied mapping. Second, they suggest that practice with dual-task conditions is not sufficient to produce automaticity since automaticity developed after 6 days of dual-task practice in Experiment 1 but not in Experiment 2. It is possible, however, that more extensive practice with dual-task conditions and varied mapping might produce automaticity (cf. Spelke et al., 1976). The present data indicate only that in the short run, practice with consistent mapping is more effective in producing automaticity. The third experiment provided further evidence of its effectiveness.

\section{Experiment 3}

\section{Results}

Choice task. The mean reaction times in each combination of choice and memory-load conditions are plotted in Figure 3. Note that for the first 5 days there was no memory task. Two aspects of the data are relevant. First, on Day 6 when the memory task was first introduced, memory load and number of alternatives may or may not interact, and second, on Day 7 when the new mapping was introduced, the interaction between memory load and number of alternatives may or may not be larger than the one on Day 6 .

The figure shows a gradual reduction in reaction time and in the effects of number of alternatives over the first 5 days of practice. On Day 6 when the memory task was first introduced, the effect of memory load appeared greater the larger the number of alternatives, but the proportionality of effects was much less prominent than on Day 7 when the new mapping was introduced.

These observations received some support in the statistical analyses. For the first 5 days, the main effect of number of alternatives was significant, $F(2,10)=29.96, p<$ .01 , as was its interaction with days, $F(8$, $40)=3.38, p<.01$. Further, there was no effect of a dummy "memory-load" factor during this period ( $F \mathrm{~S}<1$ for the main effect and the interactions). On Day 6 when the memory task was introduced, the memory-load effect with eight alternatives was not significantly larger than the effect with two alternatives, $F(1,10)=2.64, p>.05$, which reflects the outcome of a similar contrast on Day 6 of Experiment 1. The interaction between memory load, number of alternatives, and days, which reflects a "recovery of interference" on Day 7 , was not significant, $F(2,10)<1$. However, contrasts showed that the memory-load effect with eight alternatives increased from Day 6 to Day $7, F(1,10)=7.54, p<.05$, but the effect with two alternatives did not, $F(1$, $10)<1$. Note that the pattern of significance replicates the pattern from the comparable analysis in Experiment 1.

The error data, presented in Table 5, reveal similar trends.

Memory task. The mean number of digits recalled correctly in each condition on Days 6 and 7 appears in Table 5. On both days, memory performance seemed worse the 
Table 5

Proportion of Errors in Choice Task Each Day as a Function of Number of $S-R$ Alternatives (Experiment 3)

\begin{tabular}{|c|c|c|c|c|c|}
\hline \multirow[b]{2}{*}{ Day } & \multirow{2}{*}{$\begin{array}{l}\text { Memory load } \\
\text { (no. of digits) }\end{array}$} & \multicolumn{4}{|c|}{ No. of S-R alternatives } \\
\hline & & 0 & 2 & 4 & 8 \\
\hline 1 & 0 & $\ldots$ & .02 & .05 & .11 \\
\hline 2 & 0 & - & .03 & .05 & .08 \\
\hline 3 & 0 & - & .03 & .05 & .09 \\
\hline 4 & 0 & - & .04 & .03 & .05 \\
\hline 5 & 0 & - & .03 & .04 & .06 \\
\hline \multirow[t]{2}{*}{6} & 0 & - & .03 & .06 & .06 \\
\hline & 8 & $-(5.60)$ & $.03(5.62)$ & $.07(5.30)$ & $.09(5.09)$ \\
\hline \multirow[t]{2}{*}{7} & 0 & - & .04 & .05 & .10 \\
\hline & 8 & $-(6.15)$ & $.09(5.65)$ & $.10(5.20)$ & $.21(4.83)$ \\
\hline
\end{tabular}

Note. $\mathrm{S}-\mathrm{R}=$ stimulus-response. Zero $\mathrm{S}-\mathrm{R}$ alternatives represent single-task memory trials. Numbers in parentheses are mean numbers of digits recalled in correct order.

larger the number of alternatives, but the trend was stronger on Day 7 than on Day 6.

These observations were supported by statistical analysis. Fisher's LSD test revealed no significant differences between any of the conditions on Day 6 but showed that the four-choice and eight-choice conditions differed significantly from the single-task condition and that the eight-choice condition differed significantly from the two-choice condition on Day $7(p<.05)$.

\section{Discussion}

This experiment pitted practice with consistent mapping against practice with singletask conditions and found some evidence that automaticity had developed. When dual-task conditions were first introduced after 5 days of practice with consistent mapping, the interaction between memory load and number of alternatives was relatively weak; memory load increased the slope of the best fitting linear function relating reaction time to number of alternatives by $15 \mathrm{msec} /$ alternative, which was about the same as the $16 \mathrm{msec} /$ alternative increase observed on Day 4 of Experiment 1. This suggests that automaticity can develop to some extent without practice in dual-task conditions; such practice may only speed the development.

When the mapping changed on Day 7 , there was some evidence that the interaction between memory load and number of alternatives increased in magnitude, mimicking the recovery of interference observed in Experiment 1 . Memory load increased the slope by $35 \mathrm{msec} /$ alternative on Day 7 of Experiment 3 , which was about the same as the $32 \mathrm{msec} /$ alternative increase observed on Day 2 of Experiment 1. This finding suggests that practice with consistent mapping was responsible for whatever automaticity was observed on Day 6.

These conclusions, together with related conclusions from Experiments 1 and 2, suggest that practice with dual-task conditions is relatively unimportant in the development of automaticity (compare the first 2 days of practice with dual-task conditions in Experiments 1, 2, and 3; also see Bahrick et al., 1954). The arguments to the contrary by Neisser (1976) and his colleagues (Spelke et al., 1976) receive no support.

\section{General Discussion}

The theory underlying the use of the concurrent-memory-load technique as a measure of attention and automaticity predicts the existence of (a) interactions between memory load and parameters of a reaction time task, which indicate the attention demands of task components associated with those parameters, (b) additivity of effects between memory-load and reaction-time-task parameters, 
which indicates the automaticity of the associated components, and (c) a transition from interaction to additivity, which indicates the development of automaticity with practice. The experiments reported here have provided empirical support for all three predictions; interactions were found in each experiment, additivity was found in Experiment 1 (and possibly Experiment 3), and a clear transition from interaction to additivity was found in Experiment 1. Thus, the technique seems internally consistent.

The findings that bear on the relative importance of practice with consistent mapping and practice with dual-task conditions are consistent with other findings when this technique is used. Logan (1978, Experiments 1 and 2) trained two groups of subjects to perform a memory-search task with and without a concurrent memory load. One group used the same target sets throughout practice (consistent mapping), and the other used different target sets each day (varied mapping). Target-set size was varied so that the crucial interactions involved target-set size and memory load. The consistent-mapping group showed a transition from interaction to additivity, which corroborates the present Experiment 1, and the varied-mapping group showed an interaction that remained stable throughout practice, which corroborates the present Experiment 2. Together, these findings support the tentative conclusions that practice with consistent mapping may be necessary and sufficient to produce automaticity and that practice with dual-task conditions may be neither.

The present findings are also relevant to the hypothesis that attention demands in. crease with the amount of preparation necessary to enable performance on a task (Logan, 1978). The hypothesis was an attempt to resolve a paradox arising from the findings, summarized in Table 1, that memory load had a robust main effect on reaction time yet its effects were additive with respect to parameters representing each of the four major components thought to underlie performance on the task (e.g., Sternberg, 1969). Apparently, the task as a whole required attention, but its components did not. The role of attention, it was conjectured, is to assemble a set of existing automatic components, productions, or subroutines in an arrangement that satisfies novel task requirements (see Carr, in press; Carr \& Bacharach, 1976). Parameters that vary the number of components or the way in which they are coordinated were expected to interact with memory load, whereas parameters that have no effect on preparation were expected to have additive effects. Indeed, the interactions and additives reported earlier may be interpreted in this way.

In the present experiments, each $S-R$ alternative in the choice task represents a unique constellation of perceptual and motor adjustments that must be made and maintained for the task to be performed correctly, and each was expected to draw on attentional capacity. The interactions suggest they did; the more of them, the more loading memory interfered. The additivity observed on Day 6 of Experiment 1 suggests that a set of $S-R$ alternatives that have been prepared together consistently throughout practice can be prepared as a whole, without considering each alternative separately; attention to the task becomes sufficient to enable the relevant set of alternatives (see Logan, 1978, Experiment 1). This possibility is discussed further in subsequent sections. The additivity on Day 6 of Experiment 1 also supports the conjecture that preparing for such tasks demands attention whereas executing them once an appropriate stimulus appears does not. At that point in practice, each $S-R$ alternative still affected the time required for execution but no longer affected the capacity required for preparation. However, it is unlikely that execution is automatic in all speeded tasks. Serial addition, for example, seems to require a number of attentional adjustments in the course of producing the final sum (Hitch, 1978).

\section{Possibility of Specific Interference}

Interpretation of the results in terms of attention and automaticity is based on the assumption that the two tasks involved did not share processing capacities other than 
attention. This section addresses the possibility that the present findings may have resulted from overloading specific capacities.

An important consideration is the involvement of verbal coding in many short-termmemory tasks (for a review, see Baddeley \& Hitch, 1974). Indeed, some investigators have suggested that tasks will interfere with (or be interfered with by) short-term memory only to the extent that they require verbal coding (e.g., Reitman, 1971; Shiffrin, 1973; also see Roediger, Knight, \& Kantowitz, 1977). Had the reaction time tasks required verbal coding, the specific capacity for such coding may have been overloaded and so may have produced the observed interference between tasks. Possibly, the consistent mapping in Experiment 1 (and Experiment 3) may have allowed subjects to develop a reliance on some other form of coding (i.e., they may rehearse the mapping codes verbally at the beginning of practice and subsequently shift to a form of spatial rehearsal, perhaps imagining each letter superimposed on the spatial position of its corresponding key). As subjects came to rely more exclusively on such coding, interference with the memory task would diminish and so produce the observed transition from interaction to additivity. In Experiment 2 , the mapping may have changed too quickly for any reliance on nonverbal coding to have developed so that interference between tasks might persist throughout practice.

This interpretation is challenged somewhat by several reports of interference between a verbal short-term-memory task and nonverbal tasks performed within the retention interval (Crowder, 1967; Reitman, 1974 ; Watkins, Watkins, Craik, \& Mazuryk, 1973; also see C. Anderson \& Craik, 1974). Such interference is typically less than that observed when verbal tasks are performed within the retention interval (Reitman, 1971, 1974), which leads investigators to suggest that verbal short-term memory relies on a specific capacity for verbal coding as well as a general attentional capacity; verbal tasks may produce more interference because they overload verbal coding capacity as well as attentional capacity (e.g., Watkins et al., 1973). Thus, the interference in the present experiments need not have resulted from overloading a specific capacity for verbal coding; it may have resulted from overloading attentional capacity, as was assumed.

However, the possibility of specific interference cannot be dismissed easily. The interference in the present studies may well have resulted from overloading verbal capacity, even if there is a general attentional capacity. Alternatively, it may have resulted from overloading some other specific capacity, neither verbal nor attentional. Moreover, the interference in other studies between verbal short-term-memory and nonverbal tasks can be interpreted differently. The tasks were nonverbal only operationally (i.e., neither stimuli nor responses were verbal); subjects were free to adopt a verbal strategy (i.e., creating names for lights and tones) and may well have done so. It is clear that more work must be done to evalwate these possibilities and to determine the range of conditions under which subjects will rely on verbal strategies.

\section{Concurrent-Memory-Load and Zero-Slope Automaticity}

Automaticity has also been identified with a slope of zero in the function relating reaction time to the number of $\mathrm{S}-\mathrm{R}$ alternatives, target-set size, array size, and so forth, and attention demand, with the amount by which the slope is greater than zero (e.g., Neisser, Novick, \& Lazar, 1963; Shiffrin \& Schneider, 1977). This, the zero-slope technique, also assumes that attentional capacity is limited and can be shared by all task components. The slope is interpreted as a measure of the interference that results from loading capacity with an additional S-R alternative, target-set member, array element, and so forth. In multiple-choice tasks, for example, each S-R alternative may require capacity so that capacity demands would be greater the larger the number of alternatives. Since, by assumption, reaction time increases in proportion to the deficit between capacity supplied and capacity demanded, reaction 
time would increase with the number of alternatives. With practice, however, each alternative would demand less capacity (by assumption) and thus reduce the total demand. The effect would be greater in conditions involving more alternatives, and as a result, performance would show more improvement the greater the number of alternatives. If the function relating reaction time to the number of alternatives were linear, the slope would approach zero with practice.

The zero-slope technique may be applied to any task in which a variable number of equivalent components draw on the same source of capacity and, in the limiting case of automaticity, can function in parallel. Thus, multiple-choice, memory-search, and visual-search tasks are appropriate candidates, but serial addition tasks are not. Although serial addition depends on a variable number of equivalent components (simple addition operations), the components must follow each other in some sequence; the limiting case of zero slope could never be attained. Moreover, the zero-slope technique seems to require the assumption that only one capacity limits performance. If more were involved, one capacity could stop influencing performance before the others, without the slope reaching zero. If that capacity were attention, automaticity would have occurred but would not have been detected.

By contrast, the concurrent-memory-load technique can be applied to any task in which some parameter is varied, and so has a broader range of application. Moreover, it is relatively comfortable with the possibility of many capacities; inferences are based on slope differences (i.e., interactions) instead of absolute slopes. In the example above, automaticity could have been detected as a slope difference of zero had dual-task conditions been included in the design.

With the zero-slope technique as well, practice with consistent mapping is important to the development of automaticity, but considerably more practice is necessary for automaticity to develop completely. In a multiple-choice task, Mowbray and Rhoades
(1959) found that several hundred sessions of practice with the same mappings $(45,000$ responses) were required to eliminate the difference between four-choice and twochoice reaction times (i.e., to produce a slope of zero). In memory search, several investigators have found slopes to approach zero after practice with consistent mapping (Corballis, 1975 ; Graboi, 1971 ; Kristofferson, 1972b, 1977; Shiffrin \& Schneider, 1977), and others have found no reduction in slope when mapping is varied trial to trial or day to day (Burrows \& Murdock, 1969; Kristofferson, 1972a). Usually more than 20 sessions of practice with consistent mapping are necessary to produce zero slopes (Kristofferson, 1977; Ross, 1970; Shiffrin \& Schneider, 1977), though Neisser et al. (1963) found a zero slope after only 10 sessions.

By contrast, with the concurrent-memoryload technique only six sessions of practice with consistent mapping were required to produce automaticity in a multiple-choice task (Experiment 1), and only four sessions of such practice were required in memory search (Logan, 1978, Experiment 1). Such substantial differences in the time course of automatization suggest that the two techniques may tap changes in the allocation of different capacities.

Multiple-choice and memory-search tasks require novel combinations of existing abilities (i.e., pressing buttons upon seeing letters) so that performance may be limited both by an executive capacity for recruiting and combining abilities and by the specific capacities of systems of perception and response recruited for the task. Practice with consistent mapping allows the subject to profit from changes in the organization of abilities and changes in the abilities themselves that reduce the load on their respective capacities. The resulting improvements in performance will be reflected in the different measures of automaticity.

The concurrent-memory-load technique may tap changes in the organization of abilities; automatization might involve a search for the combination of abilities that accomplishes the task quickly and accurately with 
the least investment of capacity. By assumption, executive capacity is used in all tasks and can be re-allocated quickly to provide an immediate, integrated response to a new task (cf. Baddeley \& Hitch, 1974; Carr, in press). The rapid changes in allocation would allow the search for an optimal organization to procede relatively quickly and to take immediate advantage of new, more economical abilities that might appear in the course of practice (i.e., the transition from verbal to spatial coding discussed earlier may save capacity).

The zero-slope technique may tap changes in specific perceptual (and motor) abilities recruited for the task; automatization may involve a search for the distribution of perceptual resources (e.g., the weighting of a set of distinctive features; J. A. Anderson, Silverstein, Ritz, \& Jones, 1977) that achieves the required discrimination quickly and accurately with the least investment of perceptual capacity (i.e., perceptual learning or tuning; cf. Carr \& Bacharach, 1976; Shiffrin \& Schneider, 1977). Specific perceptual capacities are used in some tasks but not in others and may already be tuned to familiar task environments. The allocation of perceptual capacity might change gradually, slowly accumulating the effects of regular, invariant events with very little reliance on external control. Since unique events would have little effect in the long run, gradual changes in allocation could protect existing sensitivities from disruption by unusual requirements of short-lived tasks and eventually develop new sensitivities to invariant characteristics of new task environments (see J. A. Anderson et al., 1977). Thus, the search for an optimal distribution of perceptual resources might proceed rather slowly.

The identification of concurrent-memoryload automaticity with strategic adjustment of existing abilities and of zero-slope automaticity with perceptual learning is clearly speculative and does not exclude other interpretations of the data. But since the empirical separation of strategic and structural limitations on performance would be an important step toward understanding the mechanics of thought, the possibility warrants further investigation.

\section{Conclusions}

The experiments have validated the concurrent-memory-load technique by showing that interaction, additivity, and a transition from interaction to additivity can all occur in real clata. The tentative conclusion that practice with consistent mapping seems to be a necessary and sufficient condition for producing the transition (and that practice in dual-task conditions seems neither necessary nor sufficient) relates the technique to other theory and data on attention and automaticity and attests further to its validity. The present results, in combination with previous findings, suggest that the technique taps processes of preparatory attentional control capable of fast, strategic tuning.

\section{Reference Note}

1. Logan, G. D. Attention demands of encoding and comparison in visual search. Paper presented at the meeting of the Canadian Psychological Association, Toronto, Ontario, June 1976.

\section{References}

Allport, D. A. Parallel encoding within and between elementary stimulus dimensions. Perception \& Psychophysics, 1971, 10, 104-108.

Allport, D. A., Antonis, B., \& Reynolds, P. On the division of attention: A disproof of the single channel hypothesis. Quarterly Journal of Experimental Psychology, 1972, 24, 225-235.

Anderson, C. M. B., \& Craik, F. I. M. The effect of a concurrent task on recall from primary memory. Journal of Verbal Learning and Verbal Behavior, 1974, 13, 107-113.

Anderson, J. A., Silverstein, J. W., Ritz, S. A., \& Jones, R. S. Distinctive features, categorical perception, and probability learning: Some applications of a neural model. Psychological Review, 1977, 84, 413-451.

Anderson, J. R. Language, memory, and thought. Hillsdale, N.J. : Erlbaum, 1976.

Atkinson, R. C., \& Shiffrin, R. M. Human memory: A proposed system and its control processes. In K. W. Spence \& J. T. Spence (Eds.), The psychology of learning and motivation: Advances in research and theory (Vol, 2). New York: Academic Press, 1968.

Baddeley, A. D., \& Hitch, G. J. Working memory. In G. H. Bower (Ed.), The psychology of 
learning and motivation: Advances in Research and Theory (Vol. 8). New York: Academic Press, 1974.

Bahrick, H. P., Noble, M., \& Fitts, P. M. Extratask performance as a measure of learning a primary task. Journal of Experimental Psychology, 1954, 48, 298-302.

Briggs, G. E., Peters, G. L., \& Fisher, R. P. On the locus of divided attention effects. Perception $\mathcal{F}$ Psychophysics, 1972, 11, 315-320.

Broadbent, D. E. Perception and Communication. New York: Pergamon Press, 1958.

Bryan, W. L., \& Harter, N. Studies on the telegraphic language: The acquisition of a hierarchy of habits. Psychological Review, 1899, 6, $345-375$.

Burrows, D., \& Murdock, B. B., Jr. Effects of extended practice of high-speed scanning. Journal of Experimental Psychology, 1969, 82, 231-237.

Carr, T. H. Consciousness in models of human information processing: Primary memory, executive control, and input regulation. In $\mathrm{G}$. Underwood \& X. X. Stephens (Eds.), Aspects of consciousness. New York: Academic Press, in press.

Carr, T. H., \& Bacharach, V. R. Perceptual tuning and conscious attention: Systems of input regulation in visual information processing. Cognition, 1976, 4, 281-302.

Chase, W. G., \& Simon, H. A. The mind's eye in chess. In W. G. Chase (Ed.), Visual information processing. New York: Academic Press, 1973.

Corballis, M. C. Access to memory: An analysis of recognition times. In $\mathrm{P}$. M. A. Rabbitt \& S. Dornic (Eds.), Attention and performance $V$. New York: Academic Press, 1975.

Craik, F. I. M., \& Lockhart, R. S. Levels of processing: A framework for memory research. Journal of Verbal Learning and Verbal Behavior, $1972,11,671-684$.

Crowder, R. G. Short-term memory for words with a perceptual-motor interpolated activity. Journal of Verbal Learning and Verbal Behavior, 1967, 6, 753-761.

Daniels, A. Memory, afterimage, and attention. American Journal of Psychology, 1895, 6, 558564.

Doll, T. J. Short-term retention: Preparatory set as covert rehearsal. Journal of Experimental Psychology, 1969, 82, 175-182.

Egeth, H. Attention and preattention. In G. H. Bower (Ed.), The psychology of learning and motivation (Vol. 11). New York: Academic Press, 1977.

Graboi, D. Searching for targets: The effects of specific practice. Perception \& Psychophysics, $1971,10,200-304$.

Graesser, A., \& Mandler, G. Limited processing capacity constrains the storage of unrelated sets of words and retrieval from natural categories. Journal of Experimental Psychology: Human Learning and Memory, 1978, 4, 86-100.

Griffith, D., \& Johnston, W. A. Stage 2 processing and the divided-attention effect. Memory \& Cognition, 1977, 5, 597-601.

Hick, W. E. On the rate of gain of information. Quarterly Journal of Experimental Psychology, 1952, 4, 11-26.

Hitch, G. J. The role of short-term working memory in mental arithmetic. Cognitive Psychology, 1978, 10, 302-323.

Howard, J. H. The attentional demands of negation in a memory-scanning task. Memory $\&$ Cognition, 1975, 3, 319-324.

Hyman, R. Stimulus information as a determinant of reaction time. Journal of Experimental Psychology, 1953, 45, 188-196.

James, W. The principles of psychology. New York: Holt, 1890.

Kahneman, D. Attention and effort. Englewood Cliffs, N.J.: Prentice-Hall, 1973.

Keele, S. W., \& Boies, S. J. Processing demands of sequential information. Memory \& Cognition, $1973,1,85-90$.

Kirk, R. E. Experimental design: Procedures for the behavioral sciences. Belmont, Calif.: Brooks/ Cole, 1968.

Klapp, S. T. Short-term memory as a response preparation state. Memory \& Cognition, 1976, 4 , 721-729.

Kristofferson, M. W. Effects of practice on character-classification performance. Canadian Journal of Psychology, 1972, 26, 54-60. (a)

Kristofferson, M. W. When item recognition and visual search functions are similar. Perception $\mathcal{E}$ Psychophysics, 1972, 12, 379-384. (b)

Kristofferson, M. W. The effects of practice with one positive set in a memory scanning task can be completely transferred to a different positive set. Memory \& Cognition, 1977, 5, 177-186.

Laabs, G. J., \& Stager, P. Monitoring the information-processing demands of attention switching. Canadian Journal of Psychology, 1976, 30, 47-54.

LaBerge, D. Identification of two components of the time to switch attention: A test of a serial and a parallel model of attention. In S. Kornblum (Ed.), Attention and performance $I V$. New York: Academic Press, 1973.

LaBerge, D., \& Samuels, S. J. Toward a theory of automatic information processing in reading. Cognitive Psychology, 1974, 6, 293-323.

Logan, G. D. Converging evidence for automatic perceptual processing in visual search. Canadian Journal of Psychology, 1976, 30, 193-200.

Logan, G. D. Attention in character-classification tasks: Evidence for the automaticity of component stages. Journal of Experimental Psychology: General, 1978, 107, 32-63.

McLeod, P. A dual task response modality effect: Support for multiprocessor models of attention. Quarterly Journal of Experimental Psychology, $1977,29,651-667$.

Moray, N. Where is capacity limited? A survey and a model. Acta Psychologica, 1967, 27, 84-92.

Mowbray, G. H., \& Rhoades, M. V. On the reduction of choice reaction times with practice. Quar- 
terly Journal of Experimental Psychology, 1959, 11, 16-23.

Neisser, U. Cognition and reality. San Francisco: Freeman, 1976.

Neisser, U., Novick, R., \& Lazar, R. Searching for ten targets simultaneously. Perceptual and Motor Skills, 1963, 17, 955-961.

Norman, D. A. Toward a theory of memory and attention. Psychological Review, 1968, 75, 522 536.

Posner, M. I., \& Boies, S. J. Components of attention. Psychological Review, 1971, 78, 391-408.

Posner, M. I., \& Snyder, C. R. R. Attention and cognitive control. In R. L. Solso (Ed.), Information processing and cognition: The Loyola symposium. New York: Halstead Press, 1975.

Proctor, R. W., \& Fisicaro, S. A. Time, capacity, and selection between perceptual attributes. Journal of Experimental Psychology: Human Perception and Performance, 1977, 3, 337-348.

Reitman, J. S. Mechanisms of forgetting in shortterm memory. Cognitive Psychology, 1971, 2, 185-195.

Reitman, J. S. Without surreptitious rehearsal, information in short-term memory decays. Journal of Verbal Learning and Verbal Behavior, 1974, 13, 365-377.

Roediger, H. L., Knight, S. L., \& Kantowitz, B. H. Inferring decay in short-term memory: The issue of capacity. Memory \& Cognition, 1977, 5, 167 176.

Ross, J. Extended practice with a single-character classification task. Perception \& Psychophysics, $1970,8,276-278$.

Shallice, T. Dual functions of consciousness. Psychological Review, 1972, 79, 383-393.

Shiffrin, R. M. Information persistence in shortterm memory. Journal of Experimental Psychology, 1973, 100, 39-49.

Shiffrin, R. M., \& Schneider, W. Controlled and automatic human information processing: II. Perceptual learning, automatic attending, and a general theory. Psychological Review, 1977, 84, 127-190.

Shulman, H. G., \& Fisher, R. P. Expected value as a determinant of the distribution of attention. Journal of Experimental Psychology, 1972, 93, 343-348.

Shwartz, S. P. Capacity limitations in human information processing. Memory \& Cognition, 1976, 4, 763-768.

Solomons, L. M. Automatic reactions. Psychological Review, 1899, 6, 376-394.

Spelke, E., Hirst, W., \& Neisser, U. Skills of divided attention. Cognition, 1976, 4, 215-230.

Sternberg, S. Memory scanning: Mental processes revealed by reaction-time experiments. American Scientist, 1969, 57, 421-457.

Treisman, A. M. Strategies and models of selective attention. Psychological Review, 1969, 76, 282299.

Treisman, A. M., \& Davies, A. Divided attention to ear and eye. In S. Kornblum (Ed.), Attention and performance $I V$. New York: Academic Press, 1973.

Turvey, M. T. Preliminaries to a theory of action with reference to vision. In $\mathrm{R}$. Shaw \& J. Bransford (Eds.), Perceiving, acting, and knowing. Hillsdale, N.J. : Erlbaum, 1977.

Vroon, P. A. Tapping rate as a measure of expectancy in terms of response and attention limitation. Journal of Experimental Psychology, $1973,101,183-185$.

Wanner, E., \& Shiner, S. Measuring transient memory load. Journal of Verbal Learning and Verbal Behavior, 1976, 15, 159-167.

Watkins, M. J., Watkins, O. C., Craik, F. I. M., \& Mazuryk, G. Effect of nonverbal distraction on short-term storage. Journal of Experimental Psychology, 1973, 101, 296-300.

Waugh, N. C., \& Norman, D. A. Primary memory. Psychological Review, 1965, 72, 89-104.

Received May 5, 1978 